Document downloaded from:

http://hdl.handle.net/10251/63634

This paper must be cited as:

Vikingsson, LKA.; Claessens, B.; Gómez Tejedor, JA.; Gallego Ferrer, G.; Gómez Ribelles, JL. (2015). Relationship between micro-porosity, water permeability and mechanical behavior in scaffolds for cartilage engineering. Journal of the Mechanical Behavior of Biomedical Materials. 48:60-69. doi:10.1016/j.jmbbm.2015.03.021.

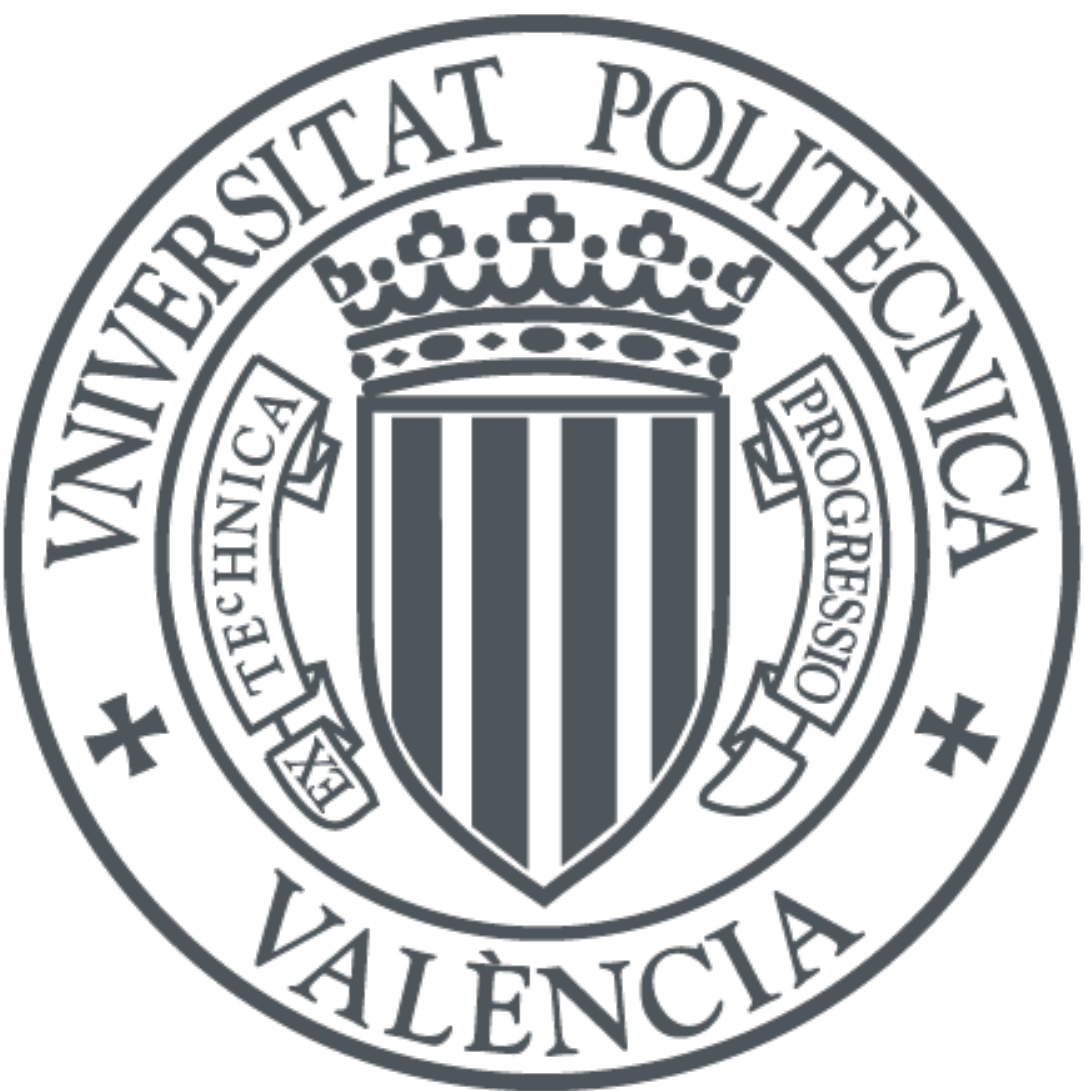

The final publication is available at

http://dx.doi.org/10.1016/j.jmbbm.2015.03.021

Copyright Elsevier

Additional Information 


\title{
Relationship between micro-porosity, water permeability and mechanical behavior in scaffolds for cartilage engineering
}

\author{
L. Vikingsson* ${ }^{1}$, B. Claessens ${ }^{1}$, , J.A. Gómez-Tejedor ${ }^{1}$, G. Gallego Ferrer ${ }^{1}{ }^{2}$ J.L. Gómez \\ Ribelles $^{1,2}$
}

${ }^{1}$ Centre for Biomaterials and Tissue Engineering, CBIT, Universitat Politècnica de València, 46022 Valencia, Spain.

${ }^{2}$ Ciber en Bioingeniería, Biomateriales y Nanomedicina (CIBER-BBN), Valencia, Spain

*Corresponding author. Tel: +34 963877007, ext.88939. Fax: +34 963877276. E-mail: livi1@upv.es

\section{Journal of the Mechanical Behavior of biomedical materials 48 (2015): 60-69}

\section{http://dx.doi.org/10.1016/i.jmbbm.2015.03.021}

\begin{abstract}
In tissue engineering the design and optimization of biodegradable polymeric scaffolds with a 3D-structure is an important field. The porous scaffold should provide the cells with an adequate biomechanical environment, allow mechanotransduction signals for cell differentiation and facilitate waste and nutrient transport. Polycaprolactone (PCL) scaffolds with a double micro- and macro-pore architecture have been proposed for cartilage regeneration. Interconnected macro pores should host the cells and new formed tissue while pore walls are microporous. This work explores the influence of pore walls microporosity on scaffold compliance and water permeability. In order to make mechanical testing representative of the outcome of the scaffold during tissue regeneration a Poly(vinyl alcohol) hydrogel with tailored mechanical modulus has been used to simulate the growing cartilage tissue inside the scaffold pores. Unconfined and confined compression tests were performed to characterize both water permeability and mechanical response of the scaffolds with varying microporosity while size and
\end{abstract}


volume fraction of macropores remains constant. The stress relaxation tests show that the stress response of the scaffold/hydrogel construct is a synergic effect from the performance of each of the components. This is interesting since it predicts that the in vivo outcome of the scaffold is not only depending on the material architecture but also the growing tissue inside the scaffolds pores. On the other hand, the confined compression results show that the compliance of the scaffold is mainly controlled by the micro porosity of the scaffold and less by the hydrogel density in the scaffold pores. These conclusions bring together valuable information for customizing the optimal scaffold and to predict the in vivo mechanical behavior.

\section{Introduction}


Osteoarthritis (OA) is one of the most common diseases in developed countries ${ }^{1}$. Only in the US over 27 million people is affected and seek treatment for the loss of cartilaginous tissue ${ }^{2}$ and the total cost is estimated to US $\$ 128$ billion ${ }^{3}$. In Spain OA affects $10 \%$ of the population ${ }^{4}$ and the average annual cost for OA per patient was estimated to $€ 1502^{5}$.

Articular cartilage does not spontaneously regenerate and the clinical solutions offered today, such as microfracture, abrasion chondroplasty, drilling or mature chondrocyte implantation, mostly generate a fibrocartilage tissue with limited mechanical properties 6789 . The articular, or hyaline cartilage, is a specialized connective tissue with relatively few cells, chondrocytes, and an extra cellular matrix (ECM) with abundant collagen type II fibers and proteoglycan aggregates. The high content in glycosaminoglycans (GAGs) and collagen makes the tissue a hydrogel with high water sorption capacity ${ }^{1011}$. The biphasic theory is often applied to cartilage and describes a system consisting of a solid phase, $20 \%$ of the total tissue weight, and an interstitial fluid phase. Water flows through the porous solid matrix and the mechanical properties and permeability of the tissue depends highly on the concentration of ECM component $^{12} 13$.

Tissue engineering techniques aim to repair and restore damaged tissues with help of natural or synthetic biomaterials. Scaffolds are polymeric, porous and biodegradable 3D constructs and an important tool in cartilage tissue engineering. The scaffold should be able to offer an adequate biomechanical environment for the cells and newly synthesized tissue inside the scaffold. Furthermore, the interconnectivity in the macropores of the scaffolds for cartilage regeneration is essential to assure cell seeding or cell invasion from subchondral bone ${ }^{14}$. The scaffold will resemble the biphasic structure of natural cartilage with a solid part, the polymeric material and newly synthesized tissue, and a fluid part consistent of water and water-soluble substances. The growing ECM in natural articular cartilage will contribute to the mechanical performance of the tissue. The porosity of the scaffold is therefore of great importance and many experimental studies have explored the in vitro and in vivo

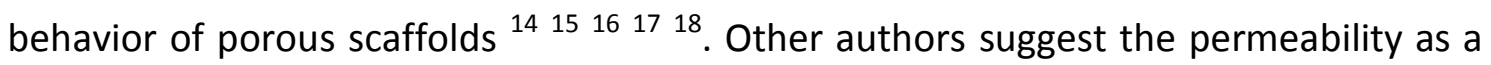


semi-quantitative parameter for porous structure of scaffolds ${ }^{19}$. We previously studied how water permeability is facilitated through an empty Poly (L-lactic acid) scaffold, if the scaffold walls are micro porous. By tailoring the macro and micro porosity of the scaffold unique mechanical and physical properties can be obtained 202122 . Other authors observed the limited role of the macro pores in a PCL scaffold for bone regeneration and suggested further studies of the scaffold properties like interconnectivity and permeability ${ }^{23}$. In other works it is seen that a low permeability in a porous PCL scaffold enhanced chondrogenesis in vitro with primary chondrocytes 24 and by measuring the permeability of the scaffold with cells it is seen how the permeability diminishes from seeding as tissue grows ${ }^{25}$. Other authors have used 3D printing techniques to produce scaffolds for bone regeneration and the permeability for those structures was evaluated experimentally and numerically by a KozenyCarmen based equation for intrinsic permeability. The results indicated that the permeability increased for increasing pore size and increased fluid viscosity and the authors reached scaffold permeability in the same order as collagen-GAG scaffolds. ${ }^{26}$ 27. $\mathrm{PCL}$ is a well used material for tissue engineering applications, with innumerous fabrication methods ${ }^{28} 29$ such as for example selective laser sintering ${ }^{30}$, solvent casting films 3132 , blends with PLA ${ }^{33} 15$, nanocomposite scaffolds 3435223621 , electrospinning 37383940 , spin coating ${ }^{41}$, hyaluronic acid coating ${ }^{42}$ or hot pressing technique ${ }^{44} 45$.

It is clear that cell growth is dependent on the scaffold geometry and permeability and this work search for an experimental model to describe this phenomenon. Biphasic theory was applied in this work to calculate the uniaxial aggregate compressive modulus and hydraulic permeability of micro porous scaffolds constructs $\begin{array}{llll}46 & 12 & 47 & 48\end{array}$ Macro and micro porous PCL scaffolds were designed and produced with three different micro porosities, maintaining the same macro porosity, and filled with an aqueous solution of poly (vinyl alcohol) (PVA). PVA has the special characteristic of 
physically cross-link with repeating cycles of freezing and thawing ${ }^{49}$. In a previous work we showed that the PCL/PVA construct reaches values of elastic modulus in the range of natural articular cartilage after 6 cycles of freezing and thawing ${ }^{16}$. By performing unconfined and confined compression tests of the different PCL/PVA constructs the permeability and mechanical behavior have been investigated. By this we aim to assign each of the parameters, macro- and micro porosity and extra cellular matrix components, their roles in the final outcome of the mechanical behavior and permeability in the scaffold/hydrogel construct. This results in an artificial model and an interesting tool to predict the in vivo behavior of an implanted scaffold with newly generated tissue inside, which differ from the experimental in vitro studies of empty scaffolds.

\section{Materials and methods}

$\mathrm{PCL}$, average molecular weight $80000 \mathrm{Da}(\mathrm{Mw} / \mathrm{Mn}<2)$, was obtained from Sigma Aldrich (Spain). Microspheres of Elvacite 2043 (a mixture of low molecular weight poly (ethyl methacrylate) (PEMA) and poly (methyl methacrylate) (PMMA)) with diameters ranging from 120 to $200 \mu \mathrm{m}$ were purchased from Lucite International (USA). We will call them porogen microspheres hereafter. 1,4 Dioxane from Sigma Aldrich (Spain) was used as solvent for PCL, and ethanol (EtOH) (99\% pure) from Scharlab (Spain) was used to dissolve the dioxane and PEMA/PMMA in the freeze extraction and particle leaching process. Poly(vinyl alcohol), average Mw $130000 \mathrm{Da}, 99+\%$ hydrolyzed was purchased from Sigma Aldrich (Spain). All the chemicals were used as received and with no further modification.

\subsection{Scaffold preparation}

Solutions in 1,4 dioxane with different PCL concentrations, 15, 20 and $25 \%$ (w/w) (hereby called PCL 15/20/25\% respectively), were stirred during 24 hours until transparent and homogeneous solutions were obtained. Scaffolds with micro and macro porosity were fabricated by mixing the different solutions of PCL with porogen 
microspheres in a weight ratio of 1:1.25. Each mixture was immediately frozen with liquid nitrogen. After approximately one minute the frozen mixture was immersed in precooled ethanol and kept at $-20^{\circ} \mathrm{C}$ for three days with daily changes of EtOH. To remove the porogen microspheres the scaffolds were washed in ethanol at $40^{\circ} \mathrm{C}$ during 8 days, changing the ethanol twice every day until the ethanol did not show any leftover traces of PEMA.

The scaffolds were cut with circular stamps and surgical scalpels of $5 \mathrm{~mm}$ diameter and $2 \mathrm{~mm}$ height. The water immersion of the hydrophobic scaffolds was done by a solvent change ethanol to water. To make sure that all the pores were filled with water the scaffolds were put in water and subjected to continuous vacuum extraction. After the water immersion all samples were put in water 24 hours before the PVA filling or mechanical testing. The dimensions off the samples were measured three times before each mechanical assay to assure correct measurements.

\subsection{Hydrogel preparation}

A $10 \%$ aqueous solution of PVA was prepared by continuously stirring at $90^{\circ} \mathrm{C}$ for 1 hour and then let to cool in room temperature. The solution was poured into custom made $5 \mathrm{~mm}$ diameter wells and frozen for 12 hours in $-20^{\circ} \mathrm{C}$ and then thawed back to room temperature in a high humidity chamber for 8 hours. The freezing and thawing step was repeated six times. After the procedure the samples were measured three times to assure accurate sample dimensions.

\subsection{Scaffold / hydrogel construct}

The PVA solution was introduced into the previously water-immersed PCL scaffolds by vacuum injection and the scaffold and gel constructs were frozen and thawed during the same conditions as the PVA gels for six cycles. The effectiveness of the PVA filling was calculated by porosity measurements (Equation 1) and confirmed by cryo-SEM images. The density of the PVA solution was estimated from a $10 \%$ PVA aqueous solution with PVA density of $1.30 \mathrm{~g} / \mathrm{cm}^{3}$ and PCL density $1.146 \mathrm{~g} / \mathrm{cm}^{3} 4929$. 


$$
\begin{array}{r}
\phi=\frac{V_{\text {pores }}}{V_{\text {total }}}=\frac{V_{\text {pores }}}{V_{\text {scaffolds }}+V_{\text {pores }}} \\
V_{\text {pores }}=\frac{m_{\text {with PVA }}-m_{\text {dry }}}{\rho_{\text {PVA solution }}}(b) \\
V_{\text {scaffold }}=\frac{m_{\text {dry }}}{\rho_{\text {PCL }}} \quad \text { (c) }
\end{array}
$$

Equation 1. (a) The equation for calculating the porosity in the PCL and PVA construct (b) The volume of the PVA is calculated as the difference in mass of the filled and unfilled scaffold divided with the density of the hydrogel (c) The volume of the PCL is the weight of the dry scaffold divided by the density of the PCL.

\subsection{Mechanical testing}

\section{-Unconfined compression}

Unconfined compression tests were performed to evaluate the effect of the micro porosity of the PCL scaffolds and the PVA hydrogel inside the pores of the scaffold after six cycles of freezing and thawing. Mechanical characterization of the samples was performed using a Microtest SCM 300095 Universal testing machine (Spain) with a $15 \mathrm{~N}$ load cell. The samples were subjected to unconfined compression cycles to $15 \%$ strain at a rate of $1 \mathrm{~mm} / \mathrm{min}$, considered the physiological deformation suffered by natural cartilage 505152 , in a custom made device that allows the samples to be immersed in water during the assay. The results of this assay were used to make a stress-strain representation and to calculate the apparent modulus as the slope at $2 \%$ of deformation and the maximum stress at $15 \%$ deformation. An assay of total collapse of the samples was made to distinguish the different zones of the pore collapse. Unconfined compression tests were done for 5, 10 and 15\% of displacement and the sample was allowed to relax at those deformations for two hours ${ }^{53} 54$. A logarithmic stress-time representation gives information about the stress relaxation of the samples with time. For each assay six samples of each group were tested. A linearity test was 
done by a stress-strain representation and a linear fit between the points for $1,10,100$ and 1000 seconds of relaxation ${ }^{55}$.

\section{-Confined compression}

Confined compression tests were performed in the Microtest SCM 300095 Universal testing machine with a custom made device allowing the sample to be in confined mode during the compression. The sample was placed in a cylindrical chamber with impermeable lateral surface, and permeable bottom surface. The mechanical test consisted of a series of successive deformations at a constant speed of $1 \mathrm{~mm} / \mathrm{min}$, followed by a relaxation period of $15 \mathrm{~min}$. Five successive deformations were performed to $2,4,8,12,16$ and $20 \%$ of deformation. Six samples of each sample group were tested. Equilibrium stress - strain data were measured at the end of the

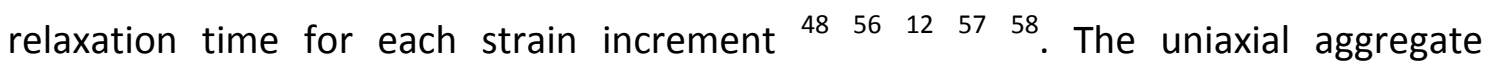
compressive modulus $\left(H_{A}\right)$ was obtained from the linear fit of thess data. Although the

relationship between the aggregate modulus and strain for large strains is not linear ${ }^{59}$ for strains up to $20 \%$ the assumption of linear behavior can be used ${ }^{60} 61$. The aggregate modulus is a measure of the compressive resistance of the solid phase at equilibrium.

According to the linear biphasic theory, stress relaxation time dependence for large times can be described by a single-exponential function with a relaxation time, $\tau$, given by equation $2^{12586220}$.

$$
\tau=\frac{h^{2}}{\pi^{2} \mathrm{H}_{\mathrm{A}} k}
$$

Equation 2. The stress relaxation time.

Where $h$ is the sample thickness, $H_{A}$ is the aggregate compressive modulus and $k$ is the hydraulic permeability in the $z$ direction. Therefore, by fitting the stress $v s$. time 
relaxation data to the single-exponential function, the relaxation time was calculated, and with it, the hydraulic permeability of the sample. Figure 3a shows the stress-strain graph with the linear fit made at the relaxation point and figure $3 \mathrm{~b}$ shows the forcetime graphs for the last four steps of relaxation in the confined compression test.

\subsection{Scanning Electron Microscopy}

The morphology of the scaffold/gel construct and the pure gel was observed by Scanning Electron Microscope (JEOL JSM-5410, Japan) equipped with a cryogenic device. Images were taken at an acceleration voltage of $15 \mathrm{kV}$. Samples were frozen at $-80^{\circ} \mathrm{C}$ and broken to see the cross-section of the samples and then sublimated for 40 minutes. The images of the PCL scaffold without PVA were taken with the same microscope without the cryogenic device.

\section{Results and discussion}

In the SEM photos of the 15, 20 and 25\% PCL scaffold (Figure 1 a-c) the macro porosity can be distinguished, showing a morphology accordingly to previous works 20214222 . The size of the macro and micro pores has been estimated by measuring 6 macro and micro pores from 3 different SEM pictures for each PCL scaffold and the minimum and maximum values are represented. The macro pores result from the extraction of the porogen microspheres and are in range of $180 \pm 60 \mu \mathrm{m}$. The micro pores are due to the freeze extraction process. The PCL solution and porogen microspheres were mixed and rapidly frozen in liquid nitrogen. When freezing the dioxane solution a solid-solid phase separation takes place and both PCL and dioxane crystallize. In the case of PCL, a semicrystalline polymer is formed. The rest of the polymer chains that stay in the amorphous phase could contain some uncrystallized dioxane but most of the dioxane crystallizes in a separated phase. ${ }^{6364}$ The frozen membrane is put into $\mathrm{EtOH}-20^{\circ} \mathrm{C}$ and the dioxane crystallites are leached out. The micro porosity is due to the cavities the dioxane leaves in the scaffolds. An increase in $\mathrm{PCL} /$ dioxane ratio decreases the 
micropore size and influences also to some extent the macro pore size, since dioxane dissolve the PMMA spheres. Consequently the macro pore size increases with decreasing PCL content. In a previous work PLLA scaffolds were made with the freeze extraction process and micro pores in the scaffolds were measured manually with SEM photos and with Microtomography $(\mu \mathrm{CT})$. Values obtained by SEM are similar to that from the image analysis made from $\mu \mathrm{CT}$ scans and therefore $\mu \mathrm{CT}$ results serve to confirm the validity of SEM images analysis. The size of the micro pores were 5.64 $\mu \mathrm{m} \pm 0.46$ for a $15 \%$ PLLA scaffold and $1.29 \mu \mathrm{m} \pm 0.49$ for a $18 \%$ PLLA scaffold. ${ }^{20}$ In this work the micro porosity was appreciated from the SEM pictures and for the $15 \% \mathrm{PCL}$ the pore size range between $2-10 \mu \mathrm{m}$ and it is seen that the micro pore size diminishes with increasing PCL content. The difference in micro porosity is also visible in the photos with higher magnification (Figure $1 \mathrm{~d}$-f).
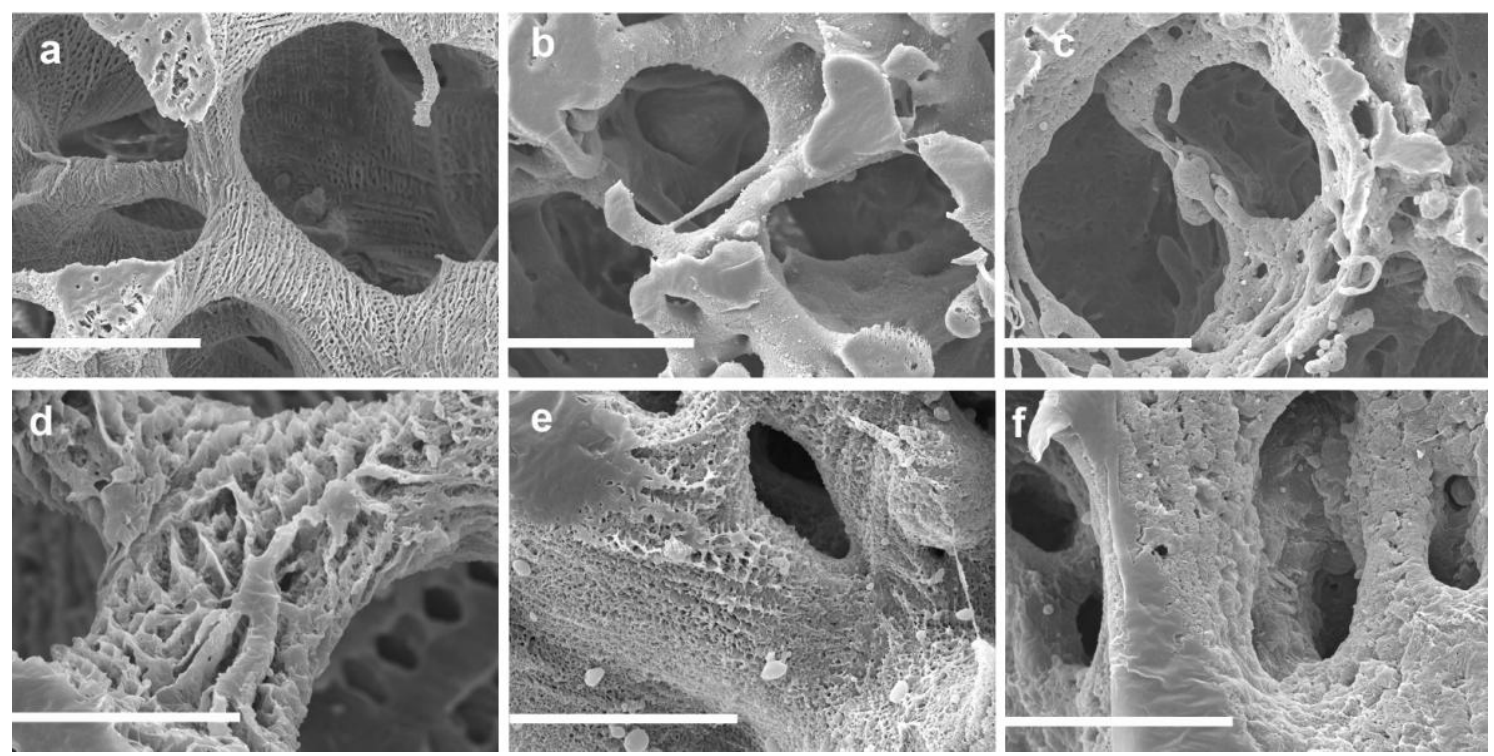

Figure 1. The PCL scaffolds showing the macro (a) $15 \%$ (b) $20 \%$ (c) $25 \%$ porosity with scale bar $100 \mu \mathrm{m}$ and micro porosity (d) $15 \%$ (e) $20 \%$ and (f) $25 \%$ scale bar $30 \mu \mathrm{m}$.

Cryo SEM photos were taken for the 15\% PCL scaffold with the PVA hydrogel filling its pores for 1, 3 and 6 cycles of freezing and thawing (Figure 2 a-c). We have previously shown that the gel enters all macro and micro pores of the PCL scaffold ${ }^{16}$. The calculated porosity according to equation 1 was zero, within the errors of the calculations, which probes the effectiveness of the vacuum filling of the PVA solution. 
PVA gels are microporous, figure 2 shows the dependence on the number of freezing and thawing cycles of the porous structure of the pristine PVA gels and also PVA gels inside the PCL scaffold. There is not much difference between the pores of the PVA gel inside the scaffold after 1 and 3 cycles of freezing and thawing, the pore size is around $1 \mu \mathrm{m}$. For 6 cycles of freezing and thawing the pore size of the PVA gel increases and there is a dispersion of pore sizes ranging from 1 to $10 \mu \mathrm{m}$ (Figure $2 \mathrm{c}$ ). Analogous behaviour is shown by the pure PVA gel (Figure $2 \mathrm{~d}$-f), although pores are larger inside the scaffold. The limitation imposed by PCL trabeculae on contraction and expansion of PVA during freezing and thawing could have some influence on the formation of micro pores.
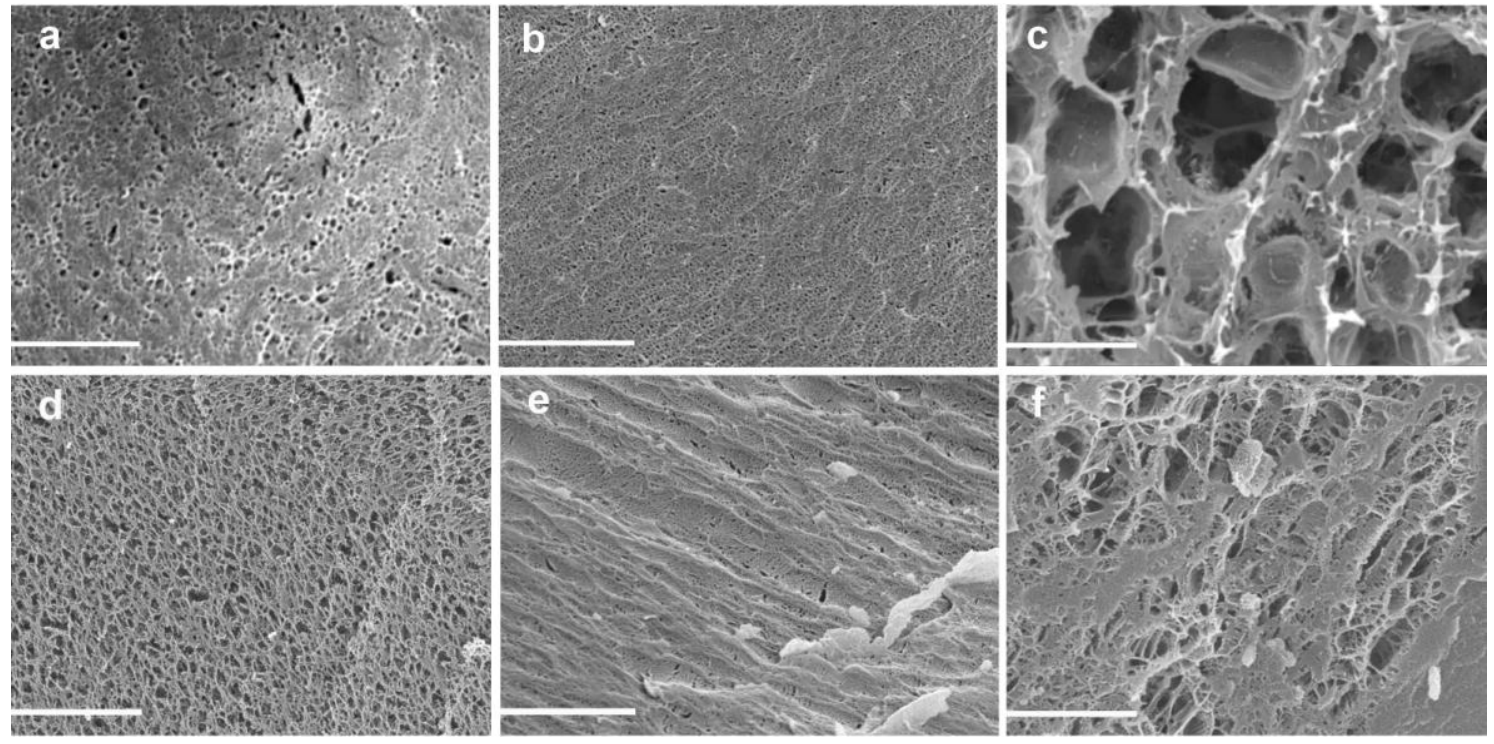

Figure 2. Cryo-SEM images of the 15\% PCL/PVA scaffolds with focus on the PVA structure, after (a) 1, (b) 3 and (c) 6 cycles of freezing and thawing. The corresponding images for pure PVA gel with 1, 3 and 6 freezing and thawing cycles are shown in (d), (e) and (f) respectively. Scale bar in the pictures $10 \mu \mathrm{m}$.

For the mechanical assays an ANOVA statistical analysis was made and when statistical difference was found an unpaired t-test was done. For each assay 6 samples of each group was tested with ANOVA test. The one way ANOVA test can compare differences between more than two groups and the t-test is considered a special case of the one 
way ANOVA and can only compare between two groups. The statistical differences are marked in the figures with asterisk or circles to distinguish the groups.

Confined compression tests were performed in all samples to evaluate the permeability of the pure PVA gel and the 15\% PCL/gel construct. Figure 3 shows the stress-strain curve used to calculate the aggregate modulus and permeability for one of the scaffolds, $20 \%$ PCL immersed in water. The confined compression test consisted of a series of successive strain ramps up to $2,4,8,12,16$ and $20 \%$ of deformation each one followed by a relaxation period of $15 \mathrm{~min}$. The values of the stress after the relaxation period was fitted to a straight line and the aggregate modulus was obtained from its slope ( Figure 3a). For the stress relaxation at 8, 12, 16 and 20\% of deformation a force-time graph was drawn ( Figure $3 b$ shows the force-time graphs for each of the stress relaxation strains). The relaxation time was calculated from the fitting to a single exponential function for large times. Permeability was calculated from equation (1). It is seen that the permeability of the pure gel is much higher than for the $15 \%$ PCL scaffold/gel construct (Figure 4a). For one cycle of freezing and thawing the permeability of the pure PVA gel is very high, the gel is barely cross-linked. For each cycle of freezing and thawing the cross-linking denstity is increasing and the gel gets stiffer ${ }^{16}$ and it is seen that the permeability is decreasing until 4 cycles of freezing and thawing where the values are in the same range. After 4 cycles of freezing and thawing it seems like the permeability of the hydrogels does not change significantly, probably due to the densely cross-linked gel. The pores are bigger (Figure 2) but the gel is more densely cross-linked and the water passage is harder. For the $15 \% \mathrm{PCL} / \mathrm{PVA}$ construct the permeability is not changing with the number of cycles of freezing and thawing. This implies that the water flux inside the scaffold filled with a hydrogel is mainly controlled by the morphology of the scaffold, and less influenced by the cross-linking density of the hydrogel. This is also supported by the results of the pure PVA gels.

As seen in figure 1 the scaffold is composed of both macro and micro pores and to evaluate how the scaffold architecture influences the permeability of a scaffold filled 
with a porous hydrogel, permeability test with different micro porosity of the PCL scaffolds were performed: 15,20 and $25 \%$ of PCL scaffolds immersed in water or filled with PVA gel with 6 cycles of freezing and thawing were tested. In figure $4 \mathrm{~b}$ it is now seen that for increasing PCL content, i.e. decreasing micro-porosity, the permeability is decreasing, showing the effect of the micro porosity on the water passage through the scaffold trabeculae. There is no statistically significant difference between the permeability of the PCL scaffold and the construct PCL/PVA after 6 cycles of freezing and thawing for any of the PCL scaffold series (Figure 4b). This indicates that the water permeability is foremost decided by the micro porosity in the pore walls. These results allows predicting that the water flux through a scaffold filled with cells and ECM (here the filling is simulated by the PVA hydrogel) is mainly controlled by the micro porosity of the scaffold, and less influenced by the macro porosity or cell or tissue density.

Figure $4 \mathrm{c}$ shows the results for the aggregate modulus for the PCL scaffolds with different micro porosity with and without hydrogel filling. The modulus is increasing for decreasing micro-porosity and there is no significant difference between the scaffold with or without PVA. The aggregate modulus for natural articular cartilage is around 0.5-0.9 $\mathrm{MPa}^{59}$ and the permeability values typically in range between $10^{-15}$ and $10^{-16} \mathrm{~m}^{4} / \mathrm{Ns}^{6547666768}$. In these terms the PCL/PVA construct can be considered a good cartilage model, specially the $25 \%$ PCL/PVA. The hydraulic pressure in cartilage depends on the proteoglycans in the ECM and is determined by pore size, pore distribution, tissue composition and mechanical deformations.

Loading and unloading tests in unconfined compression mode were performed to determine the apparent modulus and maximum stress reached for $15 \%$ of deformation for the different samples (Figure 5). A compression test until total collapse of the samples was also done to see the different zones of the stress-strain curve (Figure 6). In the results for the apparent modulus and the maximum stress it is seen that the values are increasing for increasing PCL content, i.e., decreasing micro porosity, for the water filled and PVA filled samples. Comparing the values of the apparent modulus of the scaffold with natural articular cartilage in a rabbit model 
$0.26 \pm 0.57 \mathrm{MPa}{ }^{69}$ and in humans $0.581 \pm 0.168 \mathrm{MPa}{ }^{68}$ it can be seen that all the water immersed scaffolds have values close to the animal model and the scaffolds filled with PVA gel have values similar to the natural articular cartilage of humans. In the loading path until total compression of all PCL samples immersed in water (Figure 6) it is seen that in the samples with higher PCL content the different zones of the curve are less distinguished ${ }^{70}$. This is even more pronounced by filling the pores with PVA gel. In none of the samples the trabeculae buckling and pore collapse is seen and in the samples with higher PCL content the curve is displaced to higher stress for the same deformation.

Unconfined stress relaxation tests to $5 \%, 10 \%$ or $15 \%$ compressive strain were performed for all the different PCL scaffolds filled or unfilled with PVA and for the pure PVA hydrogel. Figure 7 shows the stress-relaxation curves obtained for the $15 \% \mathrm{PCL}$ scaffold, with a deformation of $15 \%$. The experiments were performed with the samples immersed in water at room temperature. At this temperature stress relaxation of the PCL scaffold is a quite slow process. Indeed, in the performed experiment the stress is always far from equilibrium, reaching equilibrium would require a several decade time longer experiment. In a previous work ${ }^{16}$ it was shown that the apparent modulus of the PCL scaffold immersed in water did not reach values higher than that of the dry sample. This means that when the scaffold is deformed in free compression mode, water leaves the pores fast compared with the deformation rate and the mechanical behavior is dominated by the viscoelasticity of the porous polymer (i.e. by conformational rearrangements of the polymer chains and sliding of polymer crystallites). In the case of the PVA hydrogel the values of the stress for the same deformation are lower than that of the PCL but in the same order of magnitude. The stress relaxation process is still quite slow.

Interestingly enough the stress measured at short times in the composite is much higher than that of any of the two components, showing the synergic effect produced by a hindering effect of the composite structure on water permeation under compression loading. The incompressibility of water makes that any delay of water- 
flow out of the sample during compression produce an important increase of the recorded stress. In fact the water-flow though the PVA gel should be hindered by the tortuosity imposed by the trabecular structure of the hydrophobic $\mathrm{PCL}$, giving rise to a delay in the water-flow out of the scaffold/gel. Due to the hydrogel filling in the PCL scaffold the water-flow in the composite is expected to be slower than the empty scaffold. Thus, the effect is an initial stiffness of the composite that is higher than that seen in any PCL scaffold or PVA gel. Then the stress relaxation follows with a progressive drop of the stress with time. The relaxation process for the PCL/PVA construct is faster than for the single components scaffold or hydrogel which show that the kinetics of the relaxation process it not controlled by the polymers itself, but the water inside it. The results must be interpreted in the sense that the observed phenomenon is dominated by the water-flow inside the sample and not by the polymer rearrangements. This means that a deformation of the sample is progressively allowed with the water-flow out of the sample.
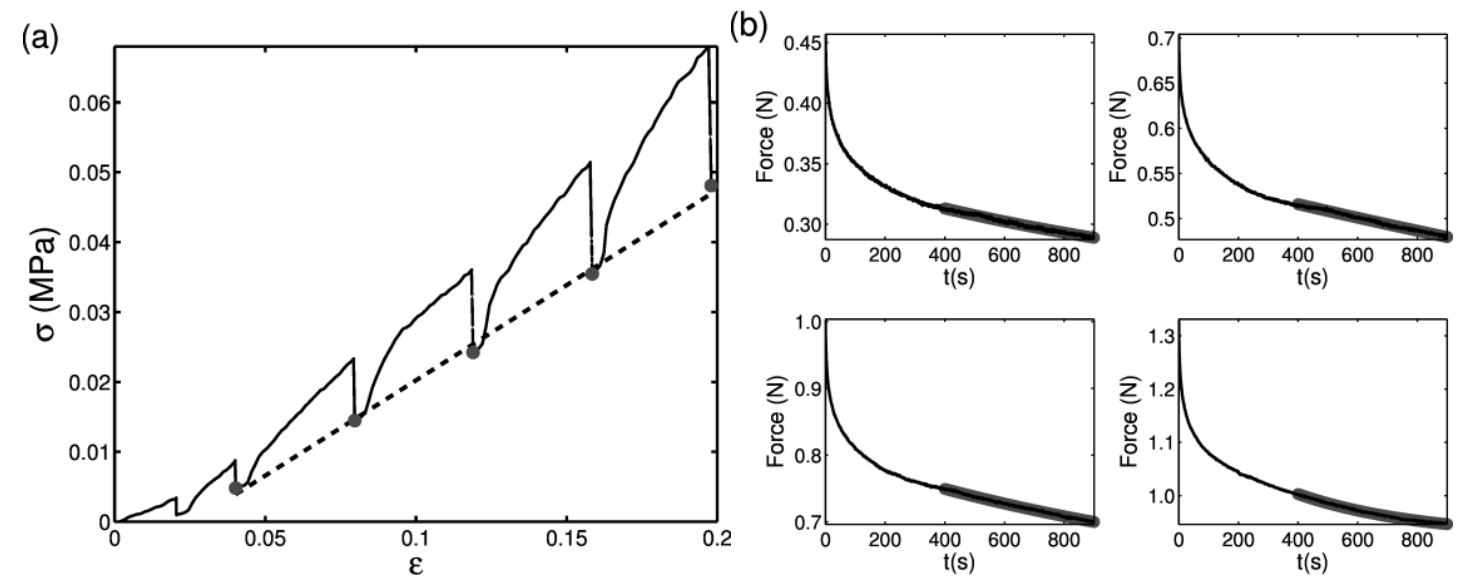

Figure 3. (a) A representative stress-strain graph from the confined compression assay for $20 \% \mathrm{PCL}$ immersed in water. The aggregate modulus is obtained as the slope from the linear fit of the stressstrain curves at equilibrium points (gray circles and dash line). (b) The force-time graphs with strain of 8 , 12,16 and $20 \%$ represented from top left to right down. The relaxation time is calculated from the fitting to a single-exponential function for large time (thick grey line). The permeability is deduced from equation (1) with the values obtained of the aggregate modulus and relaxation time. 


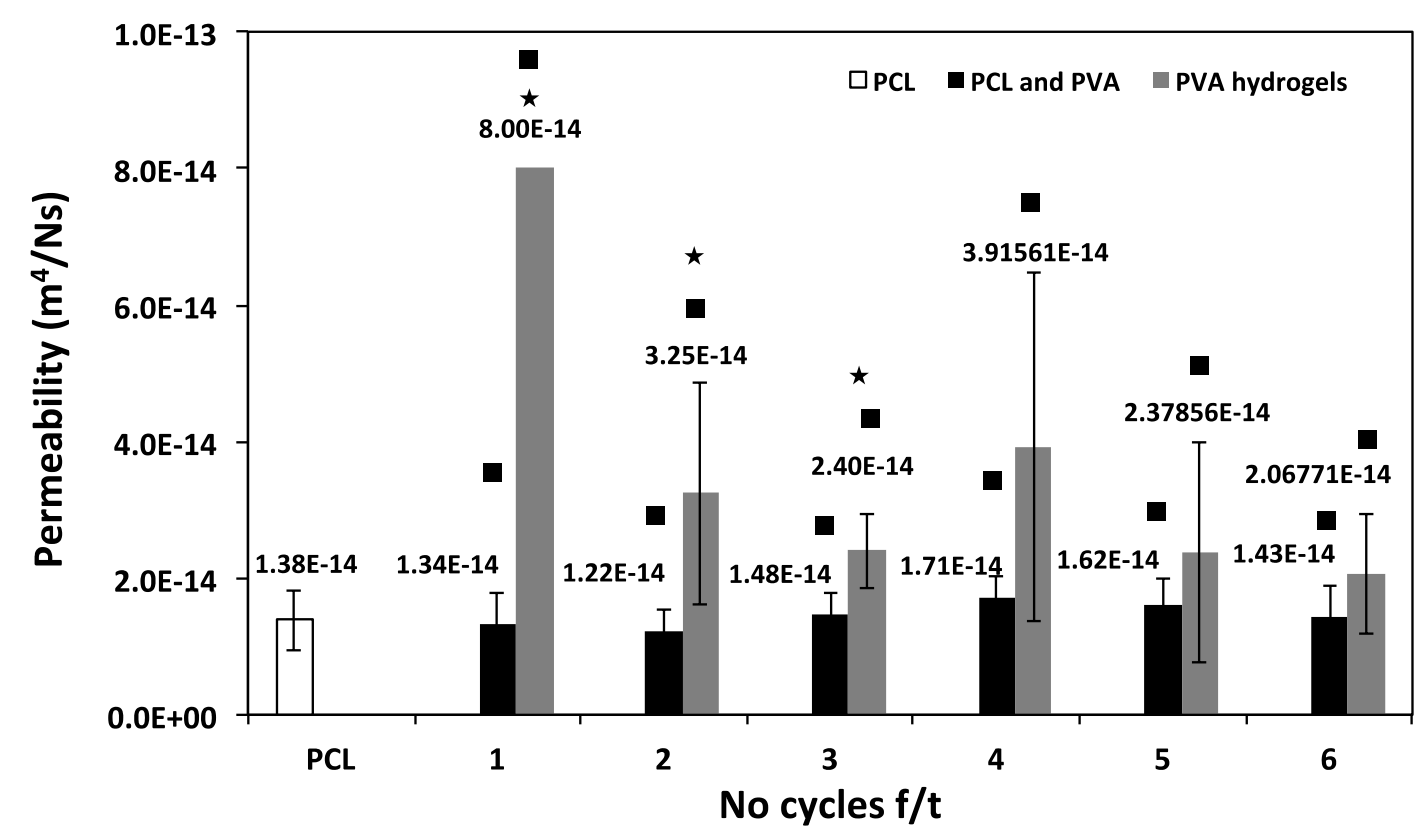

a)

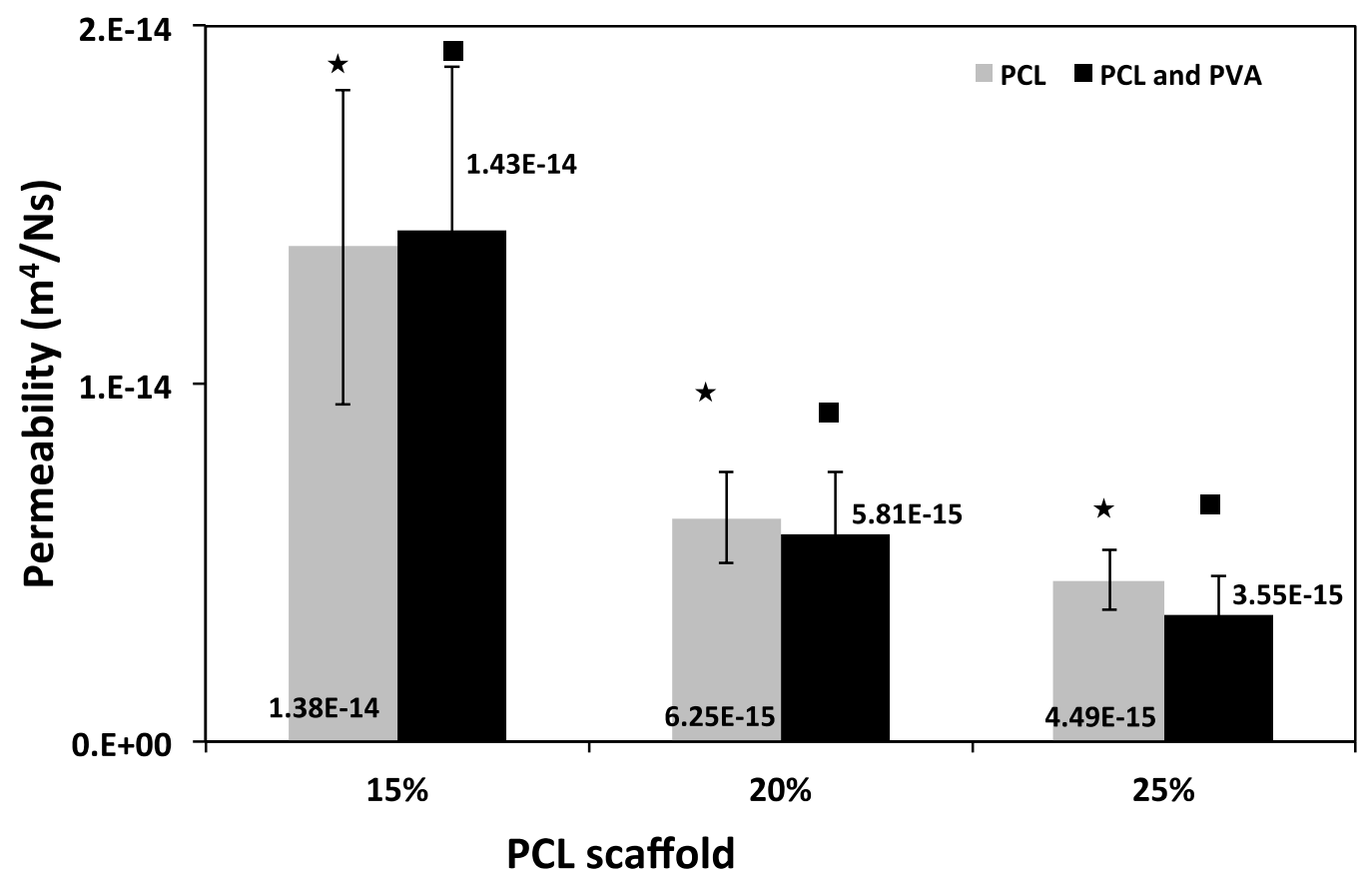

b) 


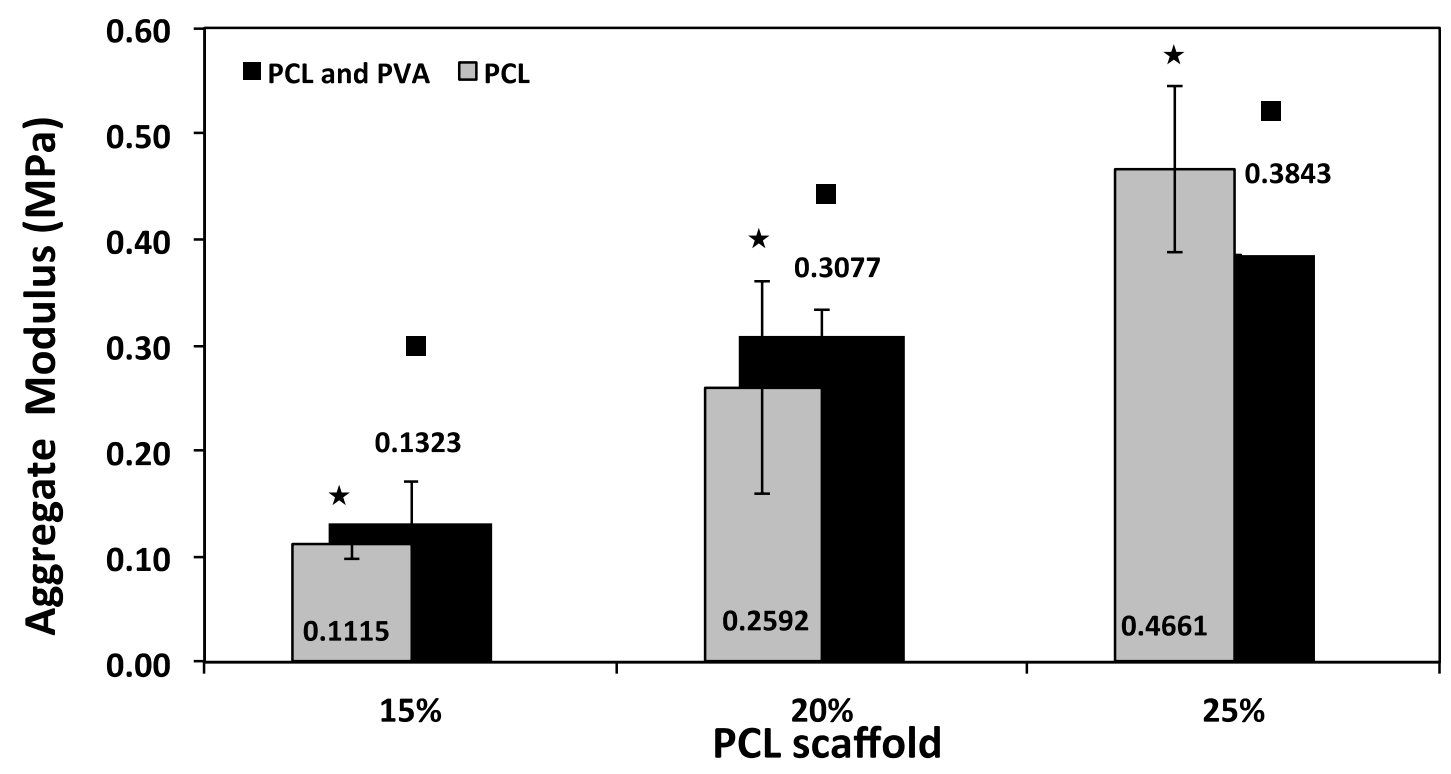

c)

Figure 4. (a) The permeability for pure PVA and 15\% PCL immersed in water and filled with PVA for 1 to 6 cycles of freezing and thawing $(\mathrm{f} / \mathrm{t})$ Annova statistical test was done, and when statistical difference was found an unpaired t-test was performed to evaluate the statistical difference between tested groups with $p<0.05$. The rectangles show significant difference between pure PVA gels and PCL/PVA constructs, and the asterix marc significant differences in the pure PVA gels.

b) The permeability and c) the aggregate modulus for the series of PCL scaffolds with and without PVA filling.. c) The astreix show significant stadistical difference between the PCL scaffolds and the rectangles show significant difference between the PCL/PVA constructs. 

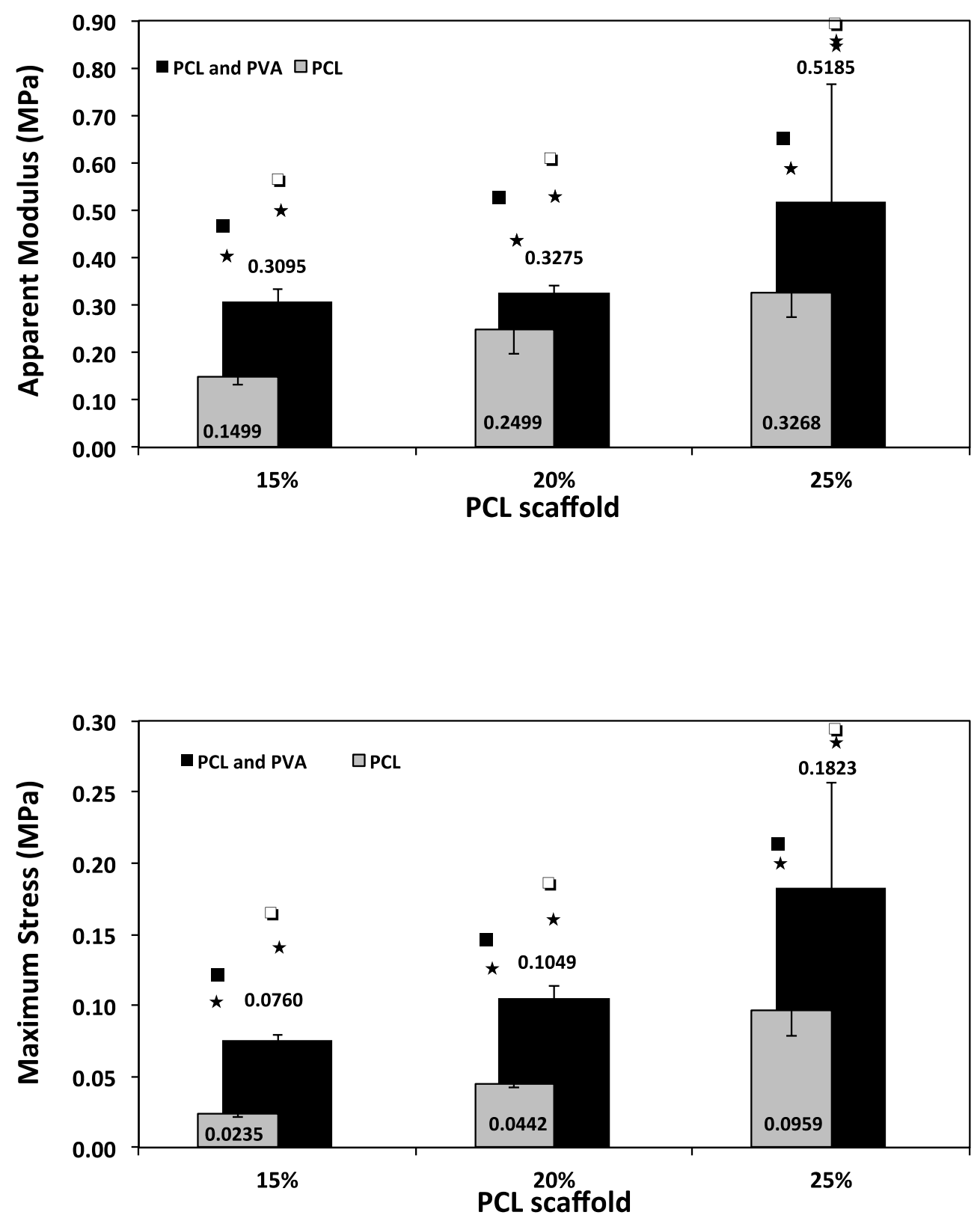

Figure 5. a) The apparent modulus for the series of PCL and PCL and PVA scaffolds. b) The stress reach at $15 \%$ strain for the series of PCL and PVA scaffolds. Annova statistical test was done, and when statistical difference was found an unpaired t-test was performed to evaluate the statistical difference between tested groups with $p<0.05$. An asterix is indicating significatnt stadistical difference between the unfilled and filled scaffolds. The filled rectangles show significant differences between the PCL scaffolds of different \%. The unfilled rectangles show significant difference between the PCL and PVA scaffolds of different \%. 


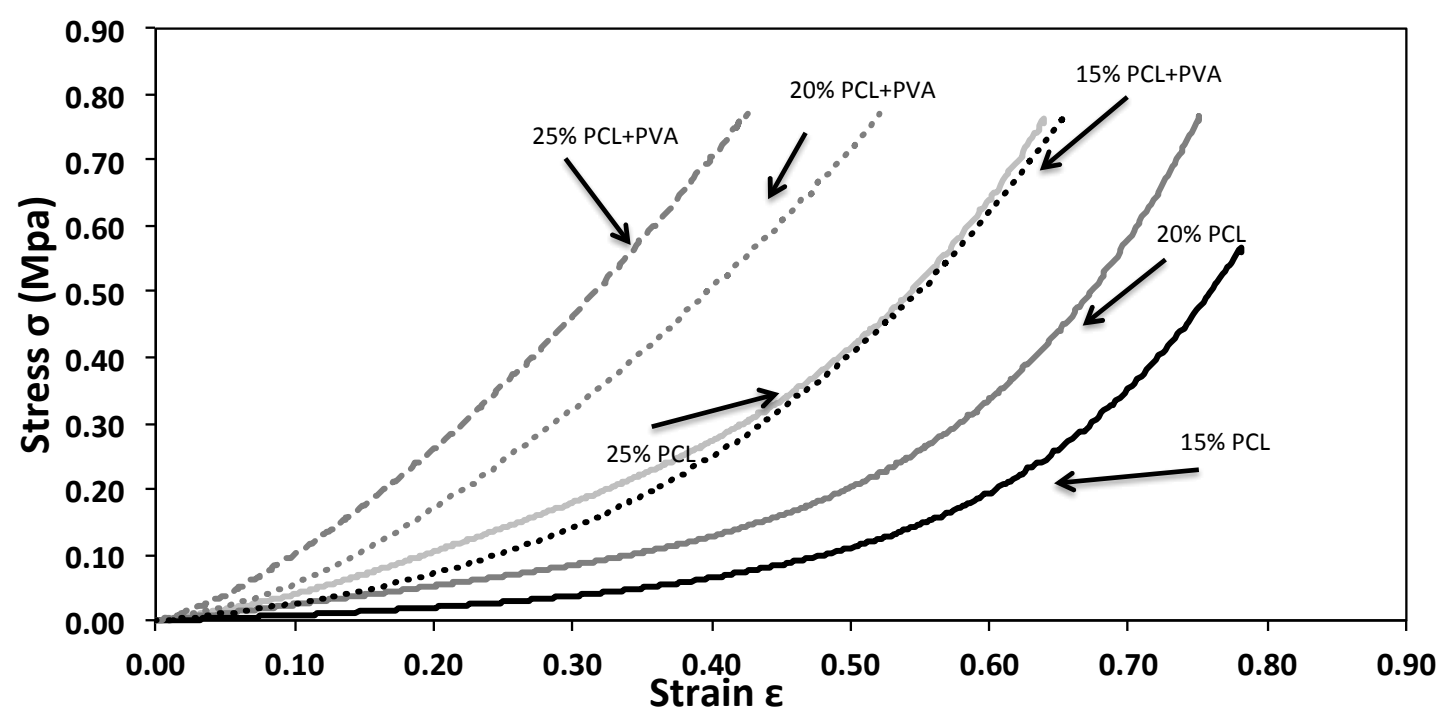

Figure 6. The loading of the PCL scaffold without (continuous line) and with PVA gel 6 cycles of $f / t$ (dash line). The black lines is $15 \%$ PCL, the dark grey lines $20 \%$ PCL and the light grey lines $25 \%$ PCL.

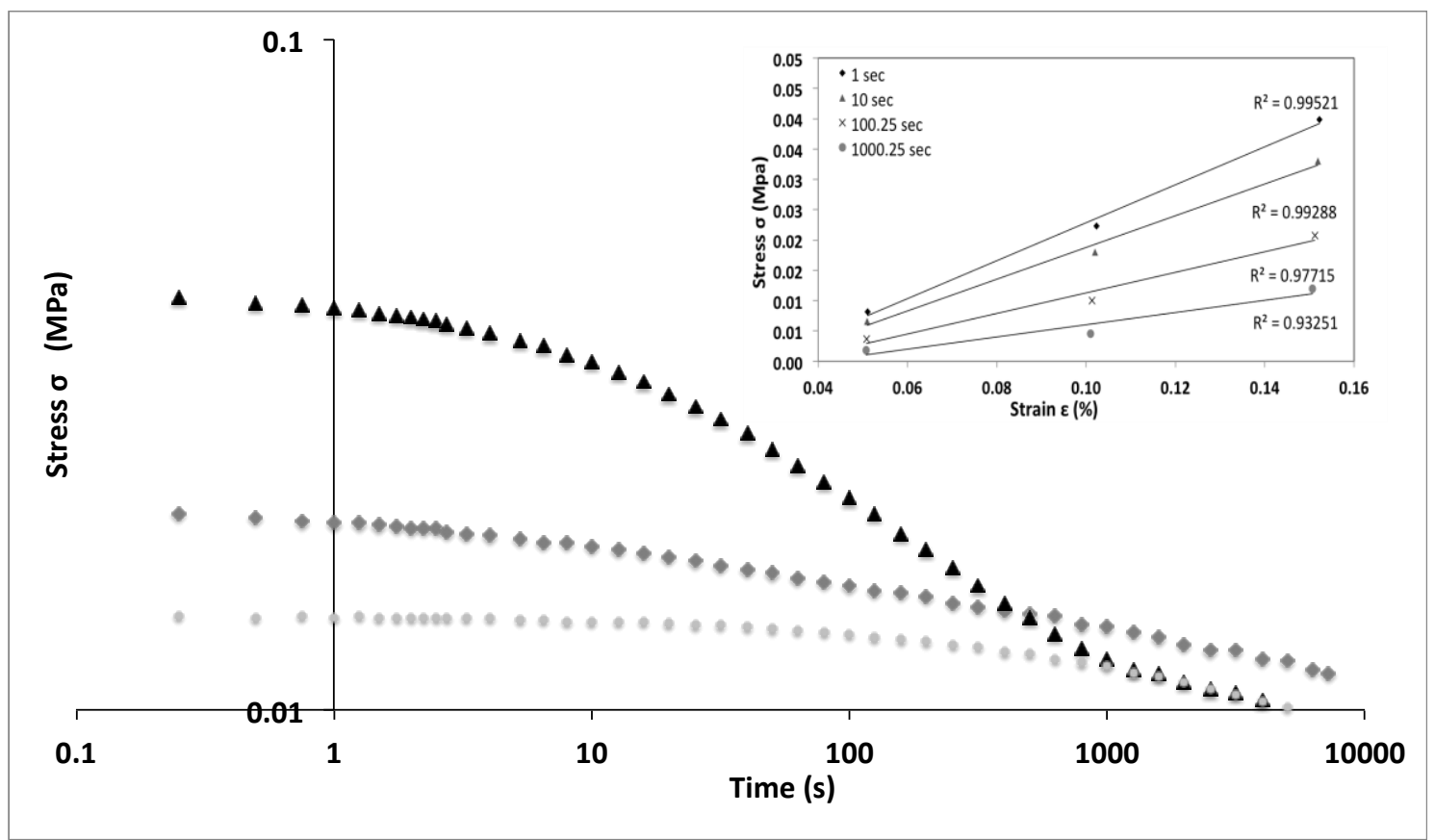


Figure 7. The logarithmic stress relaxation graphs from the compression test for the $15 \% \mathrm{PCL}$ scaffold without (grey diamonds) and with (black triangles) PVA and the pure PVA hydrogel (light grey circles) for $15 \%$ of deformation. The inset represents the stress strain graph for 1,10,100 and $1000 \mathrm{~s}$, for each time. A linear fit is represented, showing the linearity of the results.

\section{Conclusions}

This work wants to mimic the in vivo development of new-formed tissue when a biodegradable scaffold with double pore architecture is implanted in a cartilage defect and the cells inside the porous scaffold structure gradually produce new extracellular matrix. Unconfinced and confined compression tests have been performed to measure the permeability and mechanical properties of a series of PCL scaffolds with fixed macro-porosity and varying micro-porosity. The experimental model used in this work simulates the growing tissue, by a PVA hydrogel, and show that the water permeability through the scaffold/hydrogel cosntruct is highly influenced by the micro porosity of the scaffold pore walls. The 15\% PCL/PVA construct was exposed to 1-6 cycles of freezing and thawing and it is seen that the permeability of the construct is not changing with the crosslinking density of the hydrogel. When PCL scaffolds with different micro porosity is filled with a densely cross-linked gel the permeability decreases with increasing PCL content, but is not different from the unfilled scaffolds, showing that the water flow is foremost dependent on the micro porosity of the scaffolds. The stress relaxation behavior of the scaffold/hydrogel construct is higher than that of any of the single components, showing the synergic effect of the composite. This work show the importance of water mobility in scaffolds and tissue. The mechanical behavior of the scaffold implanted in a cartilage defect will not be as for the empty scaffold since the elastic modulus and mechanical resistance will depend on the water flow inside the growing tissue and scaffold pores. The permeability for natural articular cartilage is between $10^{-15}$ and $10^{-16} 6547666768$ and the values reached for the PCL/PVA model are between $1.4 \cdot 10^{-14}$ and $3.5 \cdot 10^{-15}$ for increasing PCL content. The elastic modulus for natural articular cartilage is around 0.5-0.9 $\mathrm{MPa}{ }^{59}$ and the 
values reached for the PCL/PVA model is between $0.3-0.5 \mathrm{MPa}$, giving the $25 \%$ PCL/PVA scaffold a good cartilage model.

\section{Acknowledgements}

The authors gratefully acknowledge the financial support from the Spanish Ministry of Economy and Competitiveness through the MAT2013-46467-C4-1-R project, including FEDER funds. CIBER-BBN is an initiative funded by the VI National R\&D\&I Plan 20082011, Iniciativa Ingenio 2010, Consolider Program, CIBER Actions and financed by the Instituto de Salud Carlos III with the assistance from the European Regional Development Fund.

\section{References}

1. Chen, A., Gupte, C., Akhtar, K., Smith, P. \& Cobb, J. The Global Economic Cost of Osteoarthritis: How the UK Compares. Arthritis 2012, 6 (2012).

2. Lawrence, R. C., Helmick, C. G., Arnett, F. C., Deyo, R. A. \& Felson, D. T. Estimates of the prevalence of arthritis and other rheumatic conditions in the United States. Part II. Arthritis Rheum. 58, 28-35 (2008).

3. Yelin, E. et al. National and state medical expenditures and lost earnings attributable to arthritis and other rheumatic conditions - United States. Morb. Mortal. Wkly. Rep. 56, 4-7 (2007).

4. Sociedad Española de Reumatología. Artrosis. Guía de artrosis editada por la SER www.ser.es/pacientes/enfermedades_reumaticas/artro (2014).

5. Loza, E. et al. Economic burden of knee and hip osteoarthritis in Spain. Arthritis Care Res. 61, 158-165 (2009). 
6. Steadman, J. R., Rodkey, W. G., Briggs, K. K. \& Rodrigo, J. J. The microfracture technique to treat full thickness articular cartilage defects of the knee. Orthopade 28, 26-32 (1999).

7. Insall, J. The Pridie debridement operation for osteoarthritis of the knee. Clin Orthop Relat Res 61-67 (1974).

8. Brittberg, M. Autologous chondrocyte transplantation. Clin. Orthop. Relat. Res. 367, S147-S155 (1999).

9. Hunziker, E. B. Articular cartilage repair: basic science and clinical progress. A review of the current status and prospects. Osteoarthr. Cartil. 10, 432-463 (2002).

10. Newman, A. P. Articular Cartilage Repair. Am. J. Sport. Med. 26, 309324 (1998).

11. Roughley, P. J. \& Lee, E. R. Cartilage proteoglycans: structure and potential functions. Microsc Res Tech 28, 385-397 (1994).

12. Mow, V. C., Kuei, S. C., Lai, W. M. \& Armstrong, C. G. Biphasic Creep and Stress Relaxation of Articular Cartilage in Compression: Theory and Experiments. J. Biomech. Eng. 102, 73-84 (1980).

13. Gannon, A. R., Nagel, T. \& Kelly, D. J. The role of the superficial region in determining the dynamic properties of articular cartilage. Osteoarthr. Cartil. 20, 1417-1425 (2012).

14. Hutmacher, D. W. Scaffolds in tissue engineering bone and cartilage. Biomaterials 21, 2529-2543 (2000).

15. Lebourg, M., Suay Antón, J. \& Gómez Ribelles, J. L. Porous membranes of PLLA-PCL blend for tissue engineering applications. Eur. Polym. J. 44, 2207-2218 (2008).

16. Vikingsson, L., Gallego Ferrer, G., Gómez-Tejedor, J. A. \& Gómez Ribelles, J. L. An in vitro experimental model to predict the mechanical behaviour of macroporous scaffolds implanted in articular cartilage. J. Mech. Behav. Biomed. Mater. (2014).

17. Hollister, S. J. Porous scaffold design for tissue engineering. Nat Mater 4, 518-524 (2005).

18. Hutmacher, D. W. Scaffold design and fabrication technologies for engineering tissues - state of the art and future perspectives. J Biomater Sci-Polym Ed 12, 107-124 (2001). 
19. Li, S. H., de Wijn, J. R., Layrolle, P. \& de Groot, K. Accurate geometric characterization of macroporous scaffold of tissue engineering. Key Eng. Mater. 240-242, 541-546 (2003).

20. Santamaría, V. A. et al. Influence of the macro and micro-porous structure on the mechanical behavior of poly (I-lactic acid) scaffolds. J. Non. Cryst. Solids 358, 3141-3149 (2012).

21. Deplaine, $\mathrm{H}$. et al. Biomimetic hydroxyapatite coating on pore walls improves osteointegration of poly(L-lactic acid) scaffolds. J Biomed Mater Res B Appl Biomater 101, 173-186 (2013).

22. Lebourg, M., Suay Antón, J. \& Gómez Ribelles, J. L. Hybrid structure in PCL-HAp scaffold resulting from biomimetic apatite growth. J Mater Sci Mater Med 21, 33-44 (2010).

23. Mantila Roosa, S. M., Kemppainen, J. M., Moffitt, E. N., Krebsbach, P. H. \& Hollister, S. J. The pore size of polycaprolactone scaffolds has limited influence on bone regeneration in an in vivo model. J. Biomed. Mater. Res. Part A 92A, 359-368 (2010).

24. Kemppainen, J. M. \& Hollister, S. J. Differential effects of designed scaffold permeability on chondrogenesis by chondrocytes and bone marrow stromal cells. Biomaterials 31, 279 (2010).

25. Jeong, C. G. \& Hollister, S. J. Mechanical and Biochemical Assessments of Three-Dimensional Poly(1,8-Octanediol-co-Citrate) Scaffold Pore Shape and Permeability Effects on In Vitro Chondrogenesis Using Primary Chondrocytes. Tissue Eng. Part A 16, 3759-3769 (2010).

26. Lipowiecki, M. et al. Permeability of rapid prototyped artificial bone scaffold structures. J Biomed Mater Res A. 102, 4127-4135 (2014).

27. Tierney, C. et al. The effects of collagen concentration and crosslink density on the biological, structural and mechanical properties of collagen-GAG scaffolds for bone tissue engineering. Mech Behav Biomed Mater 2, 202-209 (2009).

28. Abedalwafa, Mohammed Wang, F., Wang, L. \& Chaojing, L. BIODEGRADABLE POLY-EPSILON-CAPROLACTONE (PCL) FOR TISSUE ENGINEERING APPLICATIONS: A REVIEW. Rev. Adv. Mater. Sci. 34, (2013).

29. Labeta, Marianne Thielemans, W. Synthesis of polycaprolactone: a review. Chem. Soc. Rev. 38, 3484-3504 (2009).

30. Eosolya, S., Brabazona, D., Lohfeldb, S. \& Looneya, L. Selective laser sintering of hydroxyapatite/poly- $\varepsilon$-caprolactone scaffolds. Acta Biomater. 6, 2511-2517 (2010). 
31. Pitt, C. G., Chasalow, F. I., Hibionada, Y. M., Schindler, A. \& Klimas, D. M. Aliphatic polyesters. I. The degradation of poly( $\epsilon$-caprolactone $)$ in vivo. J. Appl. Polym. Sci. 26, 3779-3787 (1981).

32. Tang, Z. G. et al. Surface properties and biocompatibility of solvent-cast poly[-caprolactone] films. Biomaterials 25, 4741-4748 (2004).

33. Amirian, M., Chakoli, A., Cai, W. \& Sui, J. In vitro degradation of poly(Llactide)/poly(epsilon-caprolactone) blend reinforced with MWCNTs. Iran. Polym. J. 21, 165-174 (2012).

34. Wu, F., Liu, C., O’Neill, B., Wei, J. \& Ngothai, Y. Fabrication and properties of porous scaffold of magnesium phosphate/polycaprolactone biocomposite for bone tissue engineering. Appl. Surf. Sci. 258, 75897595 (2012).

35. Sarkar, S. et al. Fabrication of a Layered Microstructured Polycaprolactone Construct for 3-D Tissue Engineering. J Biomater Sci Polym Ed 19, 1347-1362 (2008).

36. Rodenas-Rochina, J., Gómez Ribelles, J. L. \& Lebourg, M. Comparative study of PCL-HAp and PCL-bioglass composite scaffolds for bone tissue engineering. J. Mater. Sci. Mater. Med. 24, 1293-1308 (2013).

37. Yoshimoto, H., Shin, Y., Terai, H. \& Vacanti, J. A biodegradable nanofiber scaffold by electrospinning and its potential for bone tissue engineering. Biomaterials 24, 2077-2082 (2003).

38. Qin, X. \& Wu, D. Effect of different solvents on poly(caprolactone) (PCL) electrospun nonwoven membranes. J. Therm. Anal. Calorim. 107, 10071013 (2012).

39. Jong, H. \& Madihally, S. Scaffold of Electrosprayed Fibers with Large Pore Size for Tissue. Acta Biomater. 6, 4734 (2010).

40. Zander, N., Orlicki, J., Rawlett, A. \& Beebe, T. J. Quantification of protein incorporated into electrospun polycaprolactone tissue engineering scaffolds. ACS Appl Mater Interfaces. 4, 2074-2081 (2012).

41. Tiaw, K., Teoh, S., Chen, R. \& Hong, M. Processing methods of ultrathin poly(epsilon-caprolactone) films for tissue engineering applications. Biomacromolecules. 8, 807-816 (2007).

42. Lebourg, M., Rochina, J. R., Sousa, T., Mano, J. \& Gómez Ribelles, J. L. Different hyaluronic acid morphology modulates primary articular chondrocyte behavior in hyaluronic acid-coated polycaprolactone scaffolds. J Biomed Mater Res A 101, 518-527 (2013). 
43. Lebourg, M. et al. Cell-free cartilage engineering approach using hyaluronic acid-polycaprolactone scaffolds: A study in vivo. J. Biomater. Appl. (2013). doi:10.1177/0885328213507298

44. Serrano, M. et al. Nitric oxide production by endothelial cells derived from blood progenitors cultured on $\mathrm{NaOH}$-treated polycaprolactone films: A biofunctionality study. Acta Biomater. 5, 2045-2053 (2009).

45. Serrano, M. et al. In vitro biocompatibility assessment of poly(epsiloncaprolactone) films using L929 mouse fibroblasts. Biomaterials 25, 56035611 (2004).

46. Setton, L. A., Zhu, W. \& Mow, V. C. The biphasic poroviscoelastic behavior of articular cartilage: role of the surface zone in governing the compressive behavior. J. Biomech. 26, 581-592 (1993).

47. Mow, V. C., Holmes, M. H. \& Lai, M. Fluid transport and mechanical properties of articular cartilage. J. Biomech. 17, 377-394 (1984).

48. Acosta Santamaría, V. A. Ingeniería de tejidos del cartílago articular: caracterización y modelado del comportamiento mecánico. (University of Zaragoza, 2011).

49. Hassan, C. M. \& Peppas, N. A. Structure and applications of Poly(vinyl alcohol) Hydrogels produced by conventional crosslinking or by freezing/thawing methods. Adv. Polym. Sci. 153, 37-65 (2000).

50. Wong, B. L. \& Sah, R. L. Effect of a focal articular defect on cartilage deformation during patello-femoral articulation. J. Orthop. Res. 28, 15541561 (2010).

51. Guilak, F., Ratcliffe, A. \& Mow, V. C. Chondrocyte deformation and local tissue strain in articular cartilage: A confocal microscopy study. J. Orthop. Res. 13, 410-421 (1995).

52. Halonen, K. S. et al. Deformation of articular cartilage during static loading of a knee joint--experimental and finite element analysis. $J$ Biomech 47, 2467-2474 (2014).

53. Guo, H., Maher, S. A. \& Torzilli, P. A. A biphasic multiscale study of the mechanical microenvironment of chondrocytes within articular cartilage under unconfined compression. J Biomech 47, 2721-2729 (2014).

54. Li, L. P., Korhonen, R. K., livarinen, J., Jurvelin, J. S. \& Herzog, W. Fluid pressure driven fibril reinforcement in creep and relaxation tests of articular cartilage. Med Eng Phys 30, 182-189 (2008).

55. Ferry, J. D. Viscoelastic Properties of Polymers 3rd Edition. (1980). 
56. Ateshian, G. \& Hung, H. The natural synovial joint: properties of cartilage. Proceeding Inst. Mech. Eng. Part J- J. Eng. Tribol. 220, 657-670 (2005).

57. Buschmann, M. D., Soulhat, J., Shirazi-Adl, A., Jurvelin, J. S. \& Hunziker, E. B. Confined compression of articular cartilage: Linearity in ramp and sinusoidal tests and the importance of interdigitation and incomplete confinemen. J. Biomech. 31, 171-178 (1998).

58. Quinn, T. M. \& Grodzinsky, A. J. Longitudinal modulus and hydraulic permeability of poly (methacrylic acid) gels: effects of charge density and solvent content. Macromolecules 26, 4332-4338 (1993).

59. Ateshian, G. A., Warden, W. H., Kim, J. J., Grelsamer, R. P. \& Mow, V. C. Finite deformation biphasic material properties of bovine articular cartilage from confined compression experiments. J. Biomech. 30, 1157-1164 (1997).

60. Lai, M. W. \& Mow, V. C. Drag-induced compression of articular cartilage during a permeation experiment. Biorheology 17, 111-123 (1980).

61. Wheaton, A. J., Dodge, G. R., Elliott, D. M., Nicoll, S. B. \& Reddy, R. Quantification of cartilage biomechanical and biochemical properties via T1 $\rho$ magnetic resonance imaging. Magn. Reson. Med. 54, 1087-1093 (2005).

62. Chin, H. C., Khayat, G. \& Quinn, T. M. Improved characterization of cartilage mechanical properties using a combination of stress relaxation and creep. J. Biomech. 44, 198-201 (2011).

63. Salmerón Sánchez, M., Monleón Pradas, M. \& Gómez Ribelles, J. L. Thermal transitions of benzene in a poly(ethyl acrylate) network. J. Non. Cryst. Solids 750-757 (2002).

64. Rault, J., Lucas, A., Neffati, R. \& Monleón Pradas, M. Thermal Transitions in Hydrogels of Poly(ethyl acrylate)/Poly(hydroxyethyl acrylate) Interpenetrating Networks. Macromolecules 30, 7866-7873 (1997).

65. Mow, V. C. \& Mansour, J. M. The permeability of articular cartilage under compressive strain and at high pressures,. J. Bone Jt. Surg. 58-A, 509516 (1976).

66. Frank, E. H. \& Grodzinsky, A. J. Cartilage electromechanics II-a continuum model of cartilage electrokinetics and correlation with experiments. J. Biomech. 20, 629-639 (1987).

67. Chen, A. C., Bae, W. C., Schinagl, R. M. \& Sah, R. L. Depth- and straindependent mechanical and electromechanical properties of full-thickness bovine articular cartilage in confined compression. J. Biomech. 34, 1-12 (2001). 
68. Jurvelin, J. S., Buschmann, M. D. \& Hunziker, E. B. Mechanical anisotropy of the human knee articular cartilage in compression. Proc. Inst. Mech. Eng. H 217, 215-219 (2003).

69. Martinez-Diaz, S. et al. In vivo evaluation of 3-dimensional polycaprolactone scaffolds for cartilage repair in rabbits. Am J Sport. Med 38, 509-519 (2010).

70. Gibson, L. \& Ashby, M. In cellular solids, structure and properties. 175 (Cambridge University Press, 1997). 